\title{
Coking properties of perhydrous low-rank vitrains. Influence of pyrolysis conditions
}

\author{
Fatima Laggoun-Défarge ${ }^{\underline{a}}$, Jean-Noël Rouzaud $\stackrel{\text { b }}{\text {, M. }}$. José Iglesias $\stackrel{\underline{c}}{\text {, Isabel Suarez-Ruiz }} \stackrel{\underline{c}}{\text {, }}$ \\ Nicolas Buillit ${ }^{\underline{a}}$ and Jean-Robert Disnar ${ }^{\underline{a}}$ \\ a ISTO (UMR 6113) CNRS-Université d'Orléans, BP 6759, 45067, Orléans cedex 2, France \\ ${ }^{\mathrm{b}}$ CRMD, UMR 6619 CNRS-Université d'Orléans, 45071, Orléans cedex 2, France \\ ${ }^{\mathrm{c}}$ Instituto Nacional del Carbon, CSIC, Ap.73, 33080, Oviedo, Spain
}

\section{Abstract}

Compositional transformations occurring during natural coalification generally lead to increased coking potential of coals characterised in the resulting cokes by large sizes of molecular orientation domains (MOD) determined through transmission electron microscopy with 002 dark field mode. In this study, two sets of perhydrous low-rank vitrains (WJV and UCV) have been pyrolysed using an open-system with two heating rates in an attempt to increase their coking potential. Results show that, despite the high potentialities of such vitrains for producing hydrocarbons, i.e. a suspensive medium efficient for their cokefaction, each of the pyrolysis methods does not lead to solid residues chemically equivalent to natural coking coals, since the cokes from these residues are always made of smaller MOD than those obtained for coking coals. For comparison, a similar characterisation, carried out on a conventional vitrain (Fouthiaux) pyrolysed in a confined-system which prevents the release of hydrocarbons, leads also to non-coking coals. The formation of such MOD is likely due to the peculiar chemical composition of the precursors and/or the pyrolysis conditions. FTIR data show that perhydrous vitrains are characterised by a low degree of condensation of aromatic units with a very small concentration of aromatic rings of large size. Thermal treatment originates depolymerisation reactions in the vitrinite network with the formation of low molecular weight products which are not efficient to form large anisotropic domains. The oxygen, present in relatively high amount in some vitrains (UCV and Fouthiaux) might also act as a crosslinking agent preventing the formation of large MOD. Furthermore, while openmedium pyrolysis leads to an important effluent release, as shown by the rapid decrease of $\mathrm{H} / \mathrm{C}$ ratio, hydrocarbon effluents are conversely retained within the coal matrix in the case of confined-medium pyrolysis. However, the latter pyrolysis induces secondary cracking reactions leading to the formation of lighter products. Therefore, the enhancement of coking properties has not been totally reached by our experiments insofar as they did not lead to oxygen-poor artificially matured coals, similar to natural coking coals.

Author Keywords: Vitrain; Pyrolysis; Chemical structure; TEM 002 dark field mode; Coking properties

\section{Introduction}

Natural coalification is a peculiar pyrolysis process which normally occurs at low temperatures $\left(<200^{\circ} \mathrm{C}\right)$ and over millions of years. Chemically, two main successive processes can be discerned: the first one corresponds to a progressive elimination of oxygenated compounds $\left(\mathrm{CO}_{2}, \mathrm{H}_{2} \mathrm{O}\right)$ without any marked loss of hydrogen, i.e. $\mathrm{O} / \mathrm{C}$ atomic 
ratio decreases whereas the $\mathrm{H} / \mathrm{C}$ ratio remains nearly constant. Then, as a result of hydrocarbon release, a steep decrease in the $\mathrm{H} / \mathrm{C}$ atomic ratio takes place $[\underline{1}, \underline{2}$ and $\underline{3}]$. The first process (oxygen release combined with maximum retention of hydrogen) leads to the formation of coking coals which are of a great economic interest especially for blast furnaces. Cokes obtained after a $1000^{\circ} \mathrm{C}$ pyrolysis of such coking coals are microtexturally characterised by large anisotropic domains which are due to the re-orientation of polyaromatic basic structural units (BSU), during a plastic stage which occurs between 450 and $500{ }^{\circ} \mathrm{C}$ [4]. The formation of large molecular orientation domains (MOD) is favoured by the presence of a high molecular weight suspensive medium (i.e. heavy polyaromatic hydrocarbons or PAH formed during pyrolysis from aromatic and/or aliphatic moieties), responsible for the plastic stage. Conversely, oxygen acts as a crosslink and prevents the development of large MOD. Thus, the amplitude of the coke domains is governed by the chemical composition of the precursors. Moreover, the size of the MOD is also dependent on pyrolysis parameters such as pressure, gas atmosphere [ㄷ], coal particle size []ㅡ, and especially the heating rate []]. These parameters act on the molecular component diffusion and then govern the solvolysing over the cross-linking ratio during pyrolysis.

In this work, the coking potential of two naturally perhydrous low-rank vitrains (WJV and UCV) characterised by abnormally low mean reflectance (suppressed reflectance) is investigated. The perhydrous character of such vitrains is supposed to confer high potentialities for producing hydrocarbons, and consequently the ability to produce a suspensive medium efficient for their cokefaction. A pyrolysis in open medium was performed on these vitrains with two heating rates to test their efficiency in generating artificially matured coals of high coking potential: (i) pyrolysis at slow heating rate of $5{ }^{\circ} \mathrm{C} / \mathrm{min}$, (ii) pyrolysis at high heating rate (more than $100^{\circ} \mathrm{C} / \mathrm{min}$ ). Such high heating rate was tested for preserving the concentration of benefic suspensive medium in the pyrolysis device as in usual cokefaction process.

A vitrinite (Fouthiaux) from conventional coals with 'normal' physico-chemical properties has been pyrolysed in confined medium and is used in this study as a reference sample.

The changes in the chemical structure of the pyrolysis residues were followed by Rock Eval pyrolysis, elemental analysis and Fourier Transform Infra Red (FTIR) spectroscopy. In addition, since the solid residues from these pyrolyses can be considered as 'artificial' higher rank coals, special attention was paid to the effect of pyrolysis conditions on the microtexture of the cokes obtained after a classical carbonisation of these residues. This later one was realised by heating the residues at $1000{ }^{\circ} \mathrm{C}$ at $4 \% \mathrm{~min}$, under conditions similar to those performed in coke ovens.

\section{Sampling, experimental procedure, and analytical methods}

\subsection{Sampling}

Two groups of naturally perhydrous vitrains were used for the experiments. Previous studies have shown that they have abnormally high content of hydrogen and volatile matter, and consequently suppress their vitrinite reflectance $[\underline{8}, \underline{9}, \underline{10}$ and $\underline{11}]$. As expected, the richness in hydrogen of these vitrains could produce an enhancement of their coking properties. The first group of samples comprises a vitrain, denoted as UCV, from the Cretaceous (Turonian) of the 
Utah basin in USA, and the second, denoted as WJV, comes from the Jurassic (Toarcian) of the Whitby basin (UK). The processes responsible for the hydrogen-enrichment of these two groups of vitrains are different and have been previously described [ $\underline{8}, \underline{9}$ and $\underline{10}]$. While UCV is hydrogen-enriched because of the resinous nature of its botanical precursors, the perhydrous character of WJV would result from an impregnation by bitumen or oil-like substances.

WJV comprises two vitrinite samples with distinctive mean reflectance values: WJVlow with $R_{\mathrm{m}}=0.22 \%$ and WJVhigh with $R_{\mathrm{m}}=0.40 \%$. Some experiments were also carried out on a blend composed of $40 \%$ of WJVlow and $60 \%$ of WJVhigh in order to test its coking properties.

The non-perhydrous vitrain used as a reference sample, Fouthiaux (Fv), comes from the Carboniferous coal formation (Stephanian) of Montceau-les-Mines in France.

\subsection{Pyrolyses}

A pyrolysis at slow heating rate was performed in an off-line open-medium system (GrayKing Assay Oven Type) following a procedure described by Suarez-Ruiz et al. [12]. Vitrinite grains $\left(\approx 1 \mathrm{~mm}\right.$ size) were placed in a quartz reactor, with a temperature range of $300-450{ }^{\circ} \mathrm{C}$. The temperature of the oven was raised from ambiant up to the operating temperature at a rate of $5{ }^{\circ} \mathrm{C} / \mathrm{min}$, then maintained isothermally for $10 \mathrm{~h}$. Experiments were carried out on WJVblend and UCV samples. The second pyrolysis, also performed in an open-medium system, was carried out with a very high heating rate (more than $100 \% \mathrm{~min}$ ). Practically, the sample was introduced in the furnace under nitrogen flow at the chosen operating temperature, i.e. at 400 and $500{ }^{\circ} \mathrm{C}$. This pyrolysis was performed on WJVlow, WJVhigh and UCV vitrains.

The reference sample (Fouthiaux) was pyrolysed in a confined-system according to the methodology described by Landais et al. [13]. Vitrinite grains $(\approx 250 \mu \mathrm{m}$ size $)$ were loaded into gold tubes and then isothermally heated at different temperatures from 300 to $450{ }^{\circ} \mathrm{C}$ during $72 \mathrm{~h}$ under constant pressure $(70 \mathrm{MPa})$ [ $\underline{14}$ and $\underline{15}]$.

Both the set of raw vitrains and solid residues resulting from pyrolyses were considered in the present study. Solid residues which have shown a maximum of generation of hydrocarbons and a pronounced plastic phase were retained for this study, i.e. those which likely have lost maximum of oxygen, and consequently are enriched in hydrogen.

\subsection{Analytical methods}

Elemental analyses were performed in a microanalyser Carlo-Erba CHS-O 1108 and RockEval pyrolysis was realised with a Vinci Technologies (Rueil-Malmaison, France) model 6 device, in accordance with Espitalié et al. [16]. Optical microscopy observations were carried out with a MPVII and DMR XP Leitz apparatus in reflected white light and in blue-violet light excitation using oil immersion objectives. The reflectance measurements were determined according to standard procedures (ISO 7404/5 1984). Solid residues were analysed by infrared spectroscopy (FTIR) using a Nicolet Magna IR560 Spectometer. An a posteriori characterisation of coking properties of artificially matured coals was carried out by studying the microtexture of their cokes [ $\underline{4}$ and $\underline{5}]$. In this aim, the raw vitrains and solid residues resulting from previous pyrolyses were heated under nitrogen $(1 \mathrm{l} / \mathrm{min})$ up to $1000{ }^{\circ} \mathrm{C}$ at a rate of $4{ }^{\circ} \mathrm{C} / \mathrm{min}$. Analyses were made on $30 \mathrm{mg}$ of powdered sample $(\approx 250 \mu \mathrm{m}$ in size $)$. 
The microtexture of the resulting cokes was studied by transmission electron microscope (TEM), using a Philips EM 400 apparatus, in the 002 dark field (DF) mode. In such conditions, the molecular orientation domains (MOD) of the cokes appear as clusters of bright dots corresponding to the BSU [4]. The MOD size was deduced by the measurement of these clusters. Microtexture can be semi-quantified using frequency histograms of MOD size. A histogram is obtained from 002 DF images of about 100 particles by comparing their MO domains to images used as standards by laboratories using this TEM technique. The conventional magnification is $23000 \times$. Ten classes are defined for the characterisation of DOM sizes: class one for the smallest MOD (MOD size $\approx 50 \AA$ ), up to class ten for the largest ones (MOD size $>1 \mu \mathrm{m})$.

\section{Results}

\subsection{Petrographic characterisation}

\subsubsection{WJV and UCV vitrains pyrolysed in open medium at slow heating rate}

The main petrographic component of the raw vitrains is dark-yellow fluorescent ulminite $(92-$ $99 \%$ vol.). Other minor components are phlobaphinite (2.6\% vol. in WJV) and resinite $(1.4 \%$ vol. in UCV) []].

The solid residues obtained after heating above $375^{\circ} \mathrm{C}$, contain homogeneous structures with large devolatilisation vacuoles. On the basis of vitrinite reflectance measurements (Table 1), solid residues should be classified as high (for the $375^{\circ} \mathrm{C}$ residue) to medium (for the $400{ }^{\circ} \mathrm{C}$ residue) volatile bituminous coals. A slight anisotropy has been observed in the samples obtained at the higher temperature. 
Table 1. $\mathrm{O} / \mathrm{H}$ atomic ratio and reflectance of raw samples and solid residues from different pyrolyses and mean sizes and classes of molecular orientation domains (MOD) of their

\begin{tabular}{|c|c|c|c|c|c|}
\hline Samples & OfH afomic rntis & $\mathrm{AOD}$ sixes $(A)$ & MOD minn classps & $\operatorname{Rm}(\phi)$ & Pyonlyais enoditiona \\
\hline WTyb-xay & 0,08 & $50-700$ & 3,5 & $0,220,4$ & \\
\hline WrVh-375 & 0,09 & $50-150$ & 19 & 0,57 & \\
\hline WrV 400 & 0.065 & $30-350$ & 23 & 144 & $\begin{array}{l}\text { Opan-systent fot slow henthy } \\
\text { vate) }\end{array}$ \\
\hline ucy-вам & 0.14 & 8100 & 1 & 0,2 & \\
\hline UCY-375 & 0,14 & $50-100$ & 1,4 & 0.76 & \\
\hline UEv 400 & 0.14 & m & $=$ & 1.01 & \\
\hline WTVhow-5x: & 0,06 & $100-359$ & 3 & 0,22 & \\
\hline WTVlow-400 & 0,06 & - & - & 0.89 & \\
\hline WIVlow-400 & 0.07 & $50-850$ & 2.8 & 1.51 & 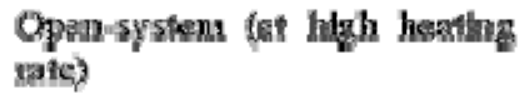 \\
\hline WTVhighnaw & 0,11 & $100-250$ & 3 & 0.4 & \\
\hline WrYhidh 400 & 0.13 & $\mathrm{~mm}$ & $=$ & 0.58 & \\
\hline WTYligh-500 & 0,15 & 30-100 & 1.3 & 1.19 & \\
\hline LeY-aw & 0,14 & 100 & 1 & 0.2 & \\
\hline UeY-190 & 0,15 & - & - & 0,61 & \\
\hline UEW 300 & 0.14 & $50-100$ & 1.7 & 142 & \\
\hline Fout, +aum & 0.13 & & 1 & 0.59 & \\
\hline Put.310 & 0,11 & $50-100$ & $15^{5}$ & 151 & Comfind-system \\
\hline Fout: 400 & 0.07 & 100 & 2 & 319 & \\
\hline
\end{tabular}

cokes 



\subsubsection{WJV and UCV vitrains pyrolysed in open medium at high heating rate}

The solid residues obtained after heating at $400{ }^{\circ} \mathrm{C}$ present very low reflectance values $(0.38$ and $0.6 \%$ ) compared to those pyrolysed at slow heating rate (Table 1). Few devolatisation vacuoles are produced at $400{ }^{\circ} \mathrm{C}$, and are more developed at $500{ }^{\circ} \mathrm{C}$. At the latter temperature, residues are slightly anisotropic, and the reflectance varies between 1.2 and $1.4 \%$ (Table 1 ) similar to that of natural coking coals.

\subsubsection{Fouthiaux vitrain pyrolysed in confined medium}

The raw vitrain is composed of nearly $100 \%$ vol. of collotelinite with a vitrinite reflectance value of $0.53 \%$. The solid residue obtained after heating at $340{ }^{\circ} \mathrm{C}$ has a reflectance value of $1.51 \%$ (Table 1). It shows many devolatilisation vacuoles and abundant 'melted forms' indicating that the completion of the plastic phase was reached. The residue obtained after heating at $400{ }^{\circ} \mathrm{C}$, has a reflectance value of $2.19 \%$, with many coalescent devolatilisation vacuoles. Unlike natural high-rank coal series, solid residues do not exhibit any anisotropy in polarised light for either of the heating temperatures investigated [14].

\subsection{Chemical evolution paths of solid residues}

The evolution of the elemental composition of the studied samples is shown in the classical atomic $\mathrm{O} / \mathrm{C}$ versus atomic $\mathrm{H} / \mathrm{C}$ Van Krevelen-type diagram presented in Fig. 1. In this diagram, the field of existence of natural humic coals of different origins is materialised by a grey strip. The artificial evolution paths delineated by the different sets of analysed samples allow the following patterns to be distinguished. A first major observation is that only the plot delineated by the Fouthiaux vitrain and the corresponding residues obtained after pyrolysis in confined-system, approximately follow the mean evolution path of natural humic coals. In itself this coincidence which results from a progressive decrease of the $\mathrm{O} / \mathrm{C}$ and $\mathrm{H} / \mathrm{C}$ atomic ratios, justifies the choice of this vitrain and of its pyrolysis residues as reference samples. The abnormally high $\mathrm{H} / \mathrm{C}$ atomic ratio values of the WJV and UCV raw vitrains depict their perhydrogenated character [8], although the UCV vitrain is more oxygenated than WJVlow and WJVhigh ( Fig. 1). Despite their initial chemical composition, all solid residues of heating in open-medium systems show a substantial decrease of their $\mathrm{H} / \mathrm{C}$ atomic ratio without appreciable decrease of their $\mathrm{O} / \mathrm{C}$ ratio. So, unlike natural coalification, our pyrolysis devices do not lead to elimination of oxygen and concentration of hydrogen, at least in the first temperature stages. 


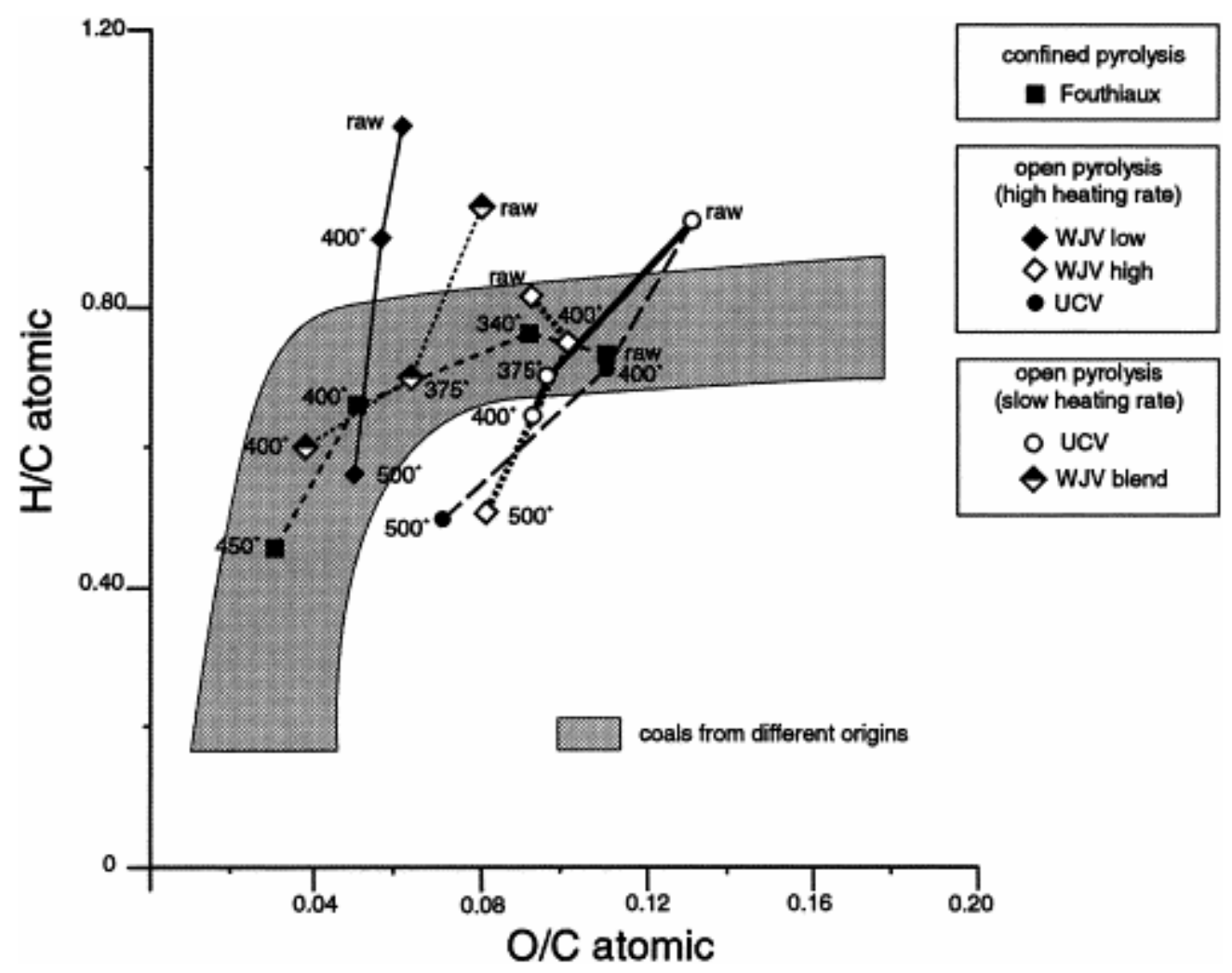

Fig. 1. Evolution of $\mathrm{H} / \mathrm{C}$ and $\mathrm{O} / \mathrm{C}$ atomic ratios of solid residues from different pyrolyses.

\subsection{Microtextural characterisation of the cokes obtained from pyrolysis residues}

The microtexture of cokes obtained after pyrolysis at $1000{ }^{\circ} \mathrm{C}$ of raw vitrains and solid pyrolyses residues was studied by transmission electron microscopy (TEM) with 002 dark field mode [4]. Indeed, previous TEM studies have demonstrated that all coals contain BSU with similar mean size $(\approx 10 \AA)$. During pyrolysis up to $1000{ }^{\circ} \mathrm{C}$ (or coalification) this size remains quasi-constant [17]. In the low-rank coals, these BSU are randomly oriented due to the presence of functional groups. The progressive elimination of these groups and progressive carbon enrichment of the material constitute the major carbonisation process. Thus it is the nature and the abundance of these groups in the precursor, which can be retained at a peculiar stage of carbonisation, i.e. plastic phase, which governs the parallelisation of the BSU and the size of the molecular orientation domains (MOD) [18]. Up to semi-anthracites, generally, the higher the coal rank (i.e. the smaller the $\mathrm{O} / \mathrm{H}$ atomic ratio), the larger the mean MOD size.

\subsubsection{Cokes from raw vitrains}

Microtextural analysis results show two groups of cokes obtained from raw vitrains (Table 1). A first group is made of the WJV cokes (low, high and blend) showing abnormally large MOD (up to $350 \AA$ in size for WJVlow; Table 1), considering the relative low-rank of their precursors $\left(R_{\mathrm{m}}\right.$ values of $0.22 \%$ for WJVlow and of $0.4 \%$ for WJVhigh). Such large MOD could be explained by the relatively low oxygen content and the richness in hydrogen of the starting material (i. 
Conversely, the second group of samples comprising Fouthiaux and UCV cokes (Table 1), only shows small MOD sizes. The UCV vitrain has a lower rank than Fouthiaux, but its coke shows slightly larger MOD: $100 \AA$ versus $50 \AA$ for the Fouthiaux coke. Again, this difference may be due to the initial chemical composition of the coke precursors. In fact, the perhydrous nature of $\mathrm{UCV}(\mathrm{H} / \mathrm{C}=0.92$ (Table 2); hydrogen INDEX=424 mg HC/g TOC) [10] and the occurrence of resinite in this vitrain $(1.4 \%$ vol.) may allow the formation of a suspensive medium favourable to the re-orientation of BSU and thus responsible for the formation of relatively larger MO domains than in Fouthiaux vitrain.

Table 2. Numerical results of FTIR (arbitrary units) and $\mathrm{H} / \mathrm{C}$ atomic ratio values of raw samples and solid residues from open system pyrolysis at high heating rate

\begin{tabular}{|c|c|c|c|c|c|c|c|}
\hline Samples & $\operatorname{Hag} \pi^{2}$ & $\mathrm{Hax}^{\mathrm{k}}$ & Han/Aal & expra & 8815 & $6750 \%$ & $\mathrm{HAC}$ \\
\hline UCV raw & 0,3 & 8.2 & 0,03 & 8 & 74 & 18 & 0,92 \\
\hline UCY 400 C & 0,5 & 5.7 & 0,09 & 18 & 57 & 25 & 0,71 \\
\hline HCV-500"C & 0.5 & 1.3 & 0.4 & 39 & 39 & 32 & 0.5 \\
\hline WIVh raw & 0.5 & 12.4 & 0.04 & 22 & 53 & 25 & 0,83 \\
\hline WJVh-400 "C & 0,7 & 9.3 & 0,08 & 23 & 51 & 26 & 0,76 \\
\hline WTVh-500 "C & 0.5 & 12 & 0.4 & 31 & 33 & 36 & 0.53 \\
\hline WIVI rawe & 0.3 & 10.9 & 0.02 & 21 & 52 & 27 & 1,07 \\
\hline WIV1 $400 " \mathrm{C}$ & 1.4 & 32.5 & 0.04 & 36 & 49 & 25 & 0.02 \\
\hline WJVl-500 "C & 0.5 & 1.6 & 0.3 & - & - & - & 0.57 \\
\hline
\end{tabular}

\subsubsection{Cokes from solid residues obtained after pyrolyses}

As mentioned above, the residues from 375 and $400{ }^{\circ} \mathrm{C}$ pyrolysis of perhydrous vitrains have shown a noticeable development of a plastic phase at these temperatures.

For pyrolysis at slow heating rate, the cokes of $375^{\circ} \mathrm{C}$ residues only show classes $1-3$, with a mean class about 1.4 for UCV and 1.9 for WJVblend (Table 1, Fig. 4d). A slight increase of the MOD size is noticed for cokes of $400{ }^{\circ} \mathrm{C}$ residues, especially for WJVblend which shows classes ranging from 1 to 4 with a mean class of about 2.3 (Table 1, Fig. 4c). However, the domain sizes of natural coking cokes are typically much larger $(\geq 1 \mu \mathrm{m})$ [4]. The small MOD size of the WJVblend is particularly suprising given their low $\mathrm{O} / \mathrm{H}$ atomic ratio values $(0.09$ and 0.06 at 375 and $400{ }^{\circ} \mathrm{C}$, respectively, Table 1). The UCV raw vitrain, despite its perhydrous character, contains a significant amount of oxygen $(\mathrm{O} / \mathrm{H}=0.14)$ which might act as a cross-linking agent preventing the formation of large MO domains. Apart from one exception (the coke obtained from the residues of pyrolysis of WJVblend at $400{ }^{\circ} \mathrm{C}$ ), the $\mathrm{O} / \mathrm{H}$ ratio did not decrease with the heat treatment, and this is consistent with the absence of any notable increase of the size of MO domains with cokefaction. 

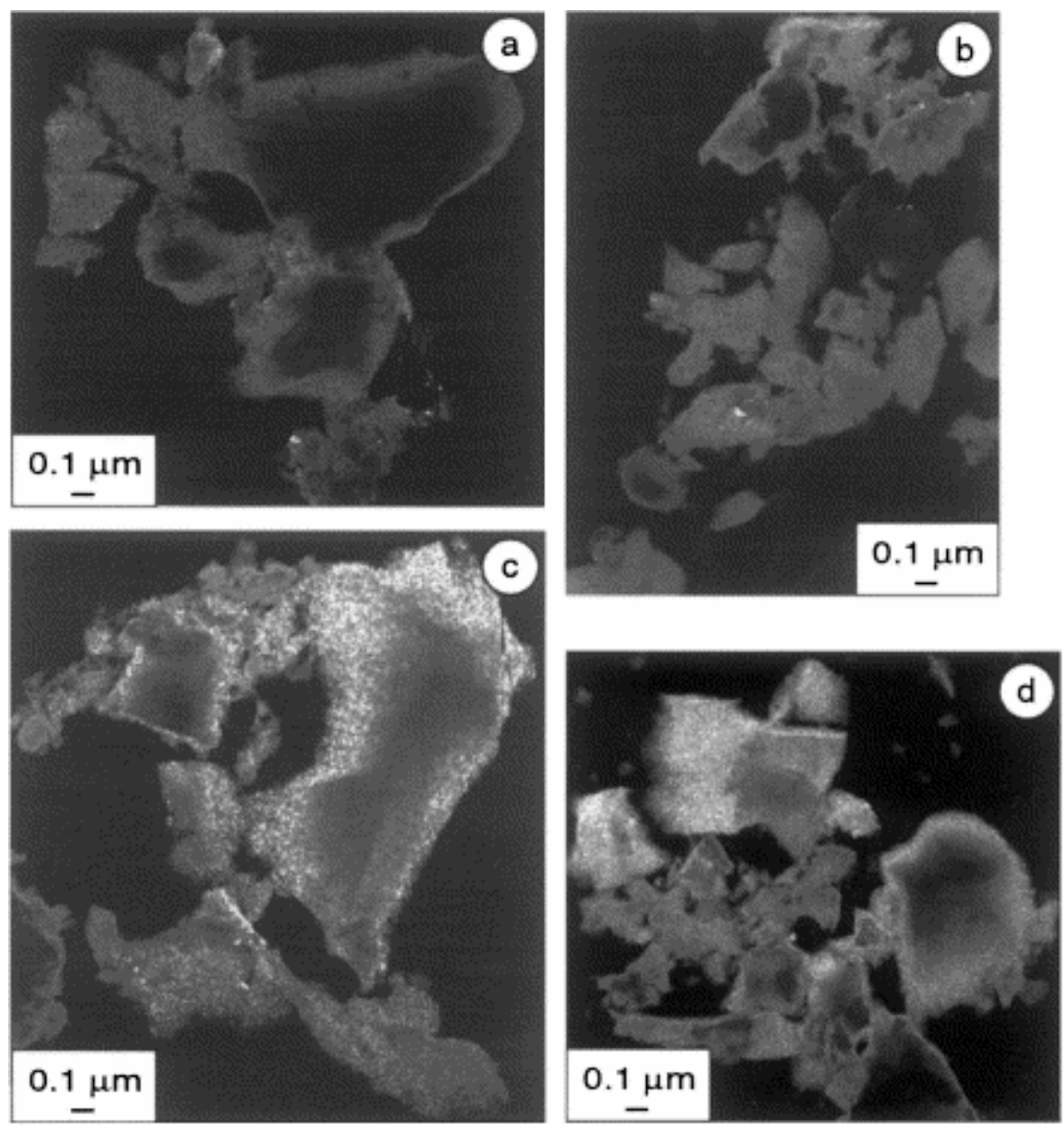

Fig. 4. Transmission electron microscopic images in 002 dark field mode of cokes obtained after pyrolysis at $1000^{\circ} \mathrm{C}$ of solid residues resulting from different pyrolyses: (a,b) open system pyrolysis (high heating rate) of WJVlow at $500{ }^{\circ} \mathrm{C}$ (a) and UCV at $500{ }^{\circ} \mathrm{C}$ (b). (c,d) Open system (pyrolysis slow heating rate) of WJVblend at $400{ }^{\circ} \mathrm{C}(\mathrm{c})$ and $\mathrm{UCV}$ at $375^{\circ} \mathrm{C}(\mathrm{d})$.

For pyrolysis at high heating rate, the domain sizes of the cokes from residues heated at $500{ }^{\circ} \mathrm{C}$ can be separated into two groups. WJVlow shows classes $1-4$, with a mean class about 2.8 (Table 1, Fig. 4a) and develops relatively large MOD, although still of smaller sizes than those of coking coals. WJVhigh and UCV show mean classes of about 1.3 and 1.7 respectively ( Table 1, Fig. 4b). These small MO domains are in accordance with their high $\mathrm{O} / \mathrm{H}$ values (about 0.14 ).

For the reference vitrain of Fouthiaux pyrolysed in confined system, whatever the pyrolysis temperature, the molecular orientation domains of the resulting cokes are always much smaller $(=100 \AA)(\underline{\text { Table } 1})$ than the domains characteristics of cokes obtained from natural coking coals which usually are $>1 \mu \mathrm{m}$. This is not consistent with the fact that solid residues of this vitrain follow the mean evolution path of natural humic coals ( $\underline{\text { Fig. 1 }}$ ).

\subsection{Fourier transformed infra red spectroscopy (FTIR)}

The FTIR results, presented in Fig. 2 and Table 2, are from the perhydrous WJV (WJVlow and WJVhigh) and UCV raw vitrains and solid residues from pyrolysis at high heating rate. The data of raw samples and those of pyrolysis residues at slow heating rate have been previously reported [ $\underline{8}$ and $\underline{9}]$. 

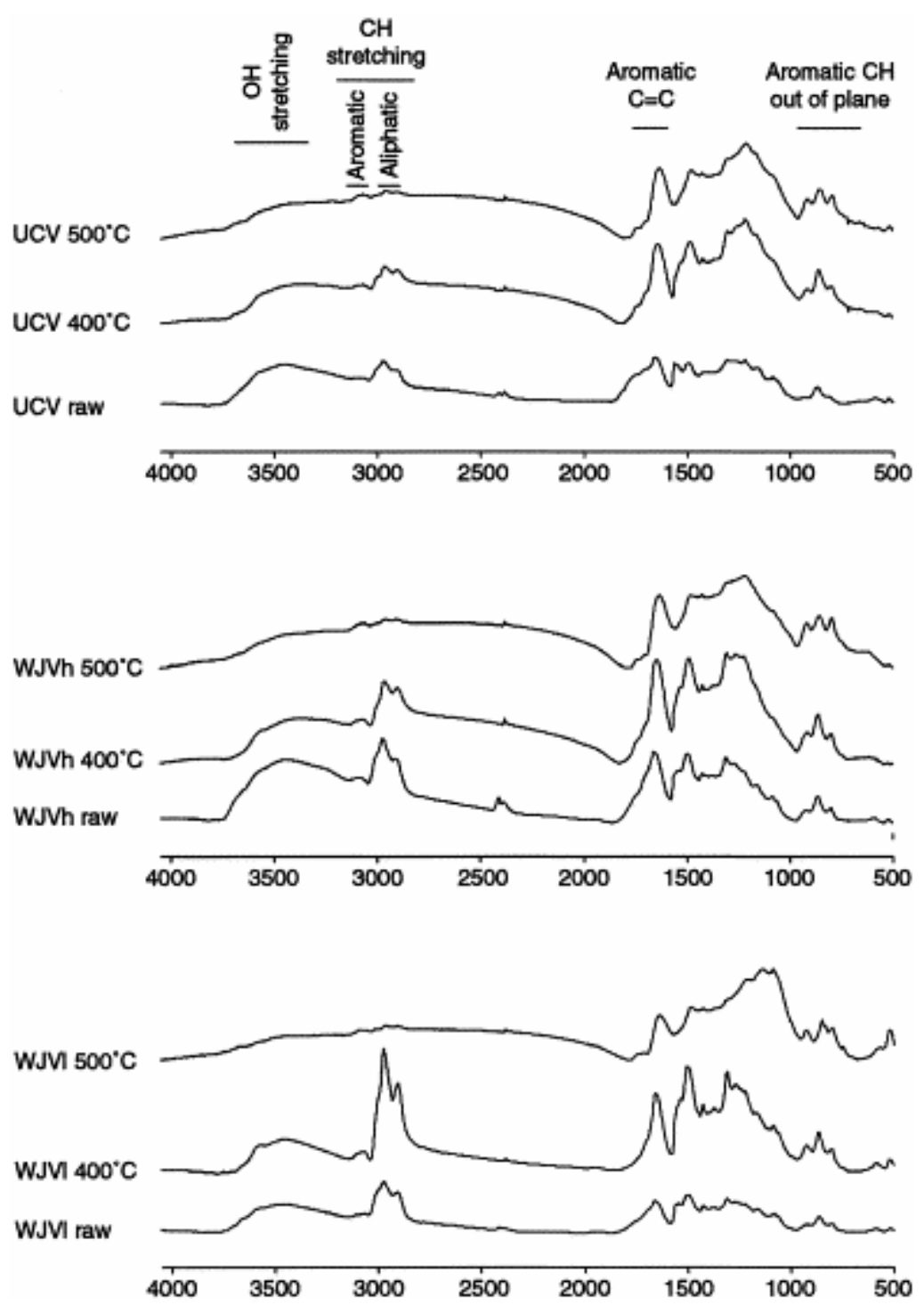

Fig. 2. Fourier transform infra red (FTIR) spectra of the WJV low, WJV high and UCV raw vitrains and solid residues obtained after pyrolysis in open medium (high heating rate). The assignations of the most useful regions for the semiquantitive analysis is depicted at the top.

The major structural units of the perhydrous raw vitrains are simple phenols with a predominance of para-alkyl substituted derivatives [9]. The presence of such structures is reflected through the clear absorption at $1500 \mathrm{~cm}^{-1}$ and, at least in part, the predominance of the $815 \mathrm{~cm}^{-1}$ mode in the $900-700 \mathrm{~cm}^{-1}$ (out-of-plane bending modes of aromatic $\mathrm{C}-\mathrm{H}$ bonds). The latter feature has been also associated to a low degree of substitution/condensation of the aromatic units in low-rank coals [19].

Thermal heating originates depolymerisation reactions in the vitrinite network with the formation and expulsion of relatively low molecular weight products. The composition of the degradation products is mainly phenolic [9] , thus explaining the lacking of the aromatic mode at $1500 \mathrm{~cm}^{-1}$ in the FTIR of the pyrolysates ( $\left.\underline{\text { Fig. } 2}\right)$.

Heating at $500{ }^{\circ} \mathrm{C}$ results in the loss of most of the aliphatic and hydroxyl groups. At the same time, the aromaticity of all the samples increases markedly to a comparable extent (see Har/Hal values in Table 2). Therefore, the FTIR spectra do not show any structural 
differences between samples. On the other hand, the moderate increase in aromaticity indicates that condensation with the formation of large aromatic cluster does not take place. Such processes were described in natural series only from the anthracite stage of coalification [20 and $\underline{21}$ ].

The influence of the thermal treatment is more clearly observed after heating at $400{ }^{\circ} \mathrm{C}$. In all cases, the relative aromaticity increases with increasing treatment, most significantly in UCV vitrinite (see Har/Hal values for the $400{ }^{\circ} \mathrm{C}$ pyrolysates in Table 2). Furthermore, the increase in aromaticity for the WJVlow and WJVhigh samples takes place without significant change in the distribution of the aromatic hydrogen, as shown by the absence of variations in the proportions of the bands at 870,815 and $750 \mathrm{~cm}^{-1}$. This could be interpreted as a result of the aromatisation of hydroxyaromatic structures [22]. Conversely, the $400{ }^{\circ} \mathrm{C} \mathrm{UCV}$ sample shows a notable modification in the aromatic hydrogen distribution. In fact, the relatively strong aromatic band at $1500 \mathrm{~cm}^{-1}$ which was present in the spectrum of the raw vitrain is lacking. A simultaneous reorganisation of the aromatic framework is suggested by the increase in the intensity of the 870 and $750 \mathrm{~cm}^{-1}$ aromatic vibration modes. The increase in the intensity of the $870 \mathrm{~cm}^{-1}$ band and the decrease in the degree of substitution of the aromatic rings, suggested by the increase in the $750 \mathrm{~cm}^{-1}$ band (four adjacent aromatic $\mathrm{CH}$ groups) (Fig. 2), have been related to the formation/development of polycyclic aromatic systems [19].

On the other hand, the decrease in the intensity of aliphatic vibration modes $(\mathrm{CH}$ stretching vibrations between 3000 and $2700 \mathrm{~cm}^{-1}$ ) in UCV and WJVhigh after heating at $400{ }^{\circ} \mathrm{C}$, indicates a decrease in the concentration of aliphatic groups as result of thermal cracking reactions (Fig. 2 and see values of Hal in Table 2). However, for WJVlow the intensity of this band sharply increases after heating to $400^{\circ} \mathrm{C}$. This could be the result of the coal softening and developing a plastic phase, more prominently in this sample than in WJVhigh and UCV.

\section{Discussion and Conclusion}

Perhydrous low-rank vitrains have been pyrolysed using an open-system with two heating rates to test their efficiency in generating residues of high coking potential. However, whatever the pyrolysis method, and despite the high potentialities of such vitrains for producing hydrocarbons, i.e. an efficient suspensive medium for their cokefaction, the resulting cokes are characterised by sizes of molecular orientation domains (MOD) much smaller than typical ones of naturally coking coals. Moreover, although the sample used as reference (Fouthiaux) approximately follows the 'normal' coal evolution trend (Fig. 1) when heated in confined medium, it also shows non-coking coal characteristics.

In the case of natural coking coals, the mean size of the coke histogram follows a decreasing sigmoïd curve with increasing $\mathrm{O} / \mathrm{H}$ ratio, i.e., with decreasing rank (ii. 3 ) [ $\underline{4}$ and $\underline{23}$ ]. Despite the much smaller MOD classes of cokes resulting from our experiments, they seem to follow a similar trend to that of coking coals ( Fig. 3). This shows the key-role of the chemical composition of the precursor for a given type (natural or artificial) of pyrolysis. The composition of the precursor indicates the potential in cross-linking atoms (oxygen, sulfur) and in heavy polyaromatic hydrocarbons. Oxygen acts as a crosslink and prevents the development of large MOD, while hydrogen acts as a suspensive medium and favours large MOD formation [ $\underline{4}$ and $\underline{23}$ ]. For some types of pyrolyses, e.g. open pyrolysis, the releases in oxygen and hydrocarbons could be concomitant whereas in Nature oxygen is eliminated before the hydrocarbons. 


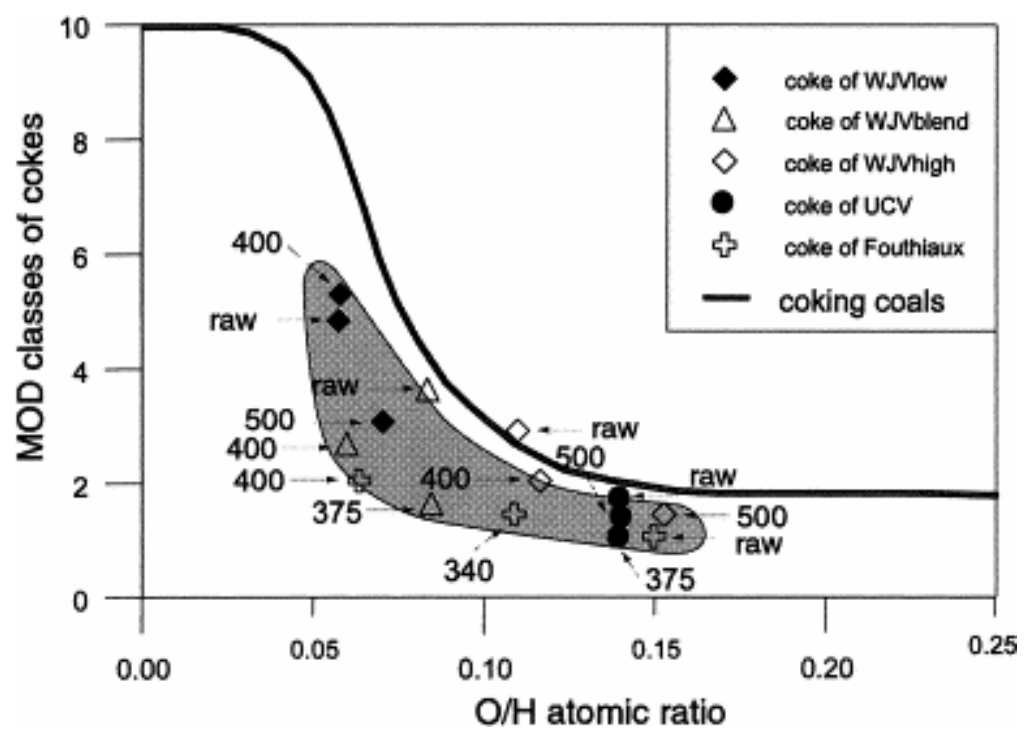

Fig. 3. Relationship between the mean size of molecular orientation domains (MOD) of the cokes obtained after pyrolysis at $1000{ }^{\circ} \mathrm{C}$ and the $\mathrm{O} / \mathrm{H}$ atomic ratio of the raw and pyrolysed vitrains - comparison with natural coking coals with increasing rank (modified after [ㄴ] ).

Thus, the formation of such MOD is due either to extraneous parameters, i.e. pyrolysis conditions and/or to intrinsic parameters, i.e. a peculiar chemical composition of the precursor.

\subsection{Influence of pyrolysis conditions}

The open medium pyrolysis leads to an important effluent release, as shown by the rapid decrease in $\mathrm{H} / \mathrm{C}$ ratio (Fig. 1), despite an initially high hydrogen content. These effluents usually generate high molecular weight suspensive medium, due to the abundance of hydrogen (aromatic and/or aliphatic) moieties. The insufficient retention of these products would have make this suspensive medium inefficient. Then, the reorientation of polyaromatic BSU have not been enough important to form large anisotropic domains.

The confined medium pyrolysis is conversely leading to a major effluent retention. This is illustrated by the evolution pathway of the Fouthiaux coal, close to the 'normal' pathway represented by the grey strip (Fig. 1). Nevertheless, the retention of such hydrocarbons within the coal matrix causes secondary cracking reactions leading to the formation of lighter products [14]. The latter, therefore, do not favour the formation of efficient suspensive medium, and the confined medium pyrolysis also generated smaller polyaromatic BSU than expected.

\subsection{Influence of initial composition}

The microtexture of the coking coals is strongly dependant on the initial vitrain composition, as the effects of autosolvolysing (hydrogenated groups) and autocross-linking (oxygen atoms) are antagonistic.

Concerning the perhydrous vitrains (WJV and UCV), the FTIR results show that the degree of condensation of aromatic structures is very low, so that they should be made up mainly by one or two aromatic rings and a very small concentration of large size aromatic rings $[\underline{8}$ and 
9]. Low molecular weight PAHs are not efficient at setting the BSU in suspension, hence leading to large MOD. Similar results were obtained by Laurent et al. on coal residues obtained by hydropyrolysis [5]. From a general point of view, in low-rank coals, oxygen is mainly contained in unstable hydroxyl, ether and carboxyl groups attached to aliphatic carbon, which are lost concomitantly mostly as $\mathrm{CO}_{2}$ and to a lesser extent, $\mathrm{H}_{2} \mathrm{O}$. This leads to a decrease in the $\mathrm{O} / \mathrm{C}$ whereas the $\mathrm{H} / \mathrm{C}$ atomic ratio remains relatively constant. Nevertheless, the characterisation of the degradation products of our samples shows that the oxygen in the raw materials is contained mainly as phenolic groups, which are more stable. Thus, the release of oxygen is due to the release of phenol derivatives in the oils [9]. This probably leads to the 'alteration' of the suspensive medium properties.

Previous studies carried out on Fouthiaux vitrain have shown that this sample is characterised by the presence of abundant phenols which may induce cross-linking reactions [15]. It has been shown also that this vitrain is a monomaceralic coal [24], without occurrence of liptinite traces-even at nanoscopic scale- [14]. This also may contribute to maintain noticeable cross-linking of carbonaceous matter because of the lack of heavy hydrocarbons which are assumed to form a suspensive medium favouring the development of large domains in the cokes [24]

\section{Acknowledgements}

This work has been financially supported by the European Community (ECSC Contract: 7220-EC-769). The authors are indebted to T. Cacciaguerra for preparation of samples for transmission electron microscopy. They also thank the referees for their constructive comments.

\section{References}

1. B.P. Tissot and D.H. Welte In: Petroleum Formation and Occurrence (2nd edition ed.), Springer-Verlag, Berlin (1984), p. 699.

2. A. Oberlin, J.-L. Boulmier and M. Villey In: B. Durand, Editor, Kerogen, Insoluble Organic Matter From Sedimentary Rocks, Technip, Paris (1980), p. 191.

3. M. Teichmuller In: A.C. Scott, Editor, Coal and Coal-Bearing Stata: Recent Advances 32, Geological Society of London, Special Publication, London (1987), p. 127.

4. J.-N. Rouzaud and A. Oberlin In: H. Charcosset, Editor, Advanced Methodologies in Coal Characterization, Elsevier, Amsterdam (1990), p. 311 Assisted by Nickel-Pepin-Donat .

5. P. Laurent, C. Braekman-Danheux and J.-N. Rouzaud Fuel 74 (1995), p. 201.

6. J.-N. Rouzaud, E. Totino, J.-M. Guet, J. Kister and J.-F. Muller Fuel Process. Technol 20 (1988), p. 133.

7. M. Villey, A. Oberlin and A. Combaz Carbon 17 (1979), p. 77. 
8. M.J. Cuesta, M.J. Iglesias, A. Jiménez, F. Laggoun-Défarge and I. Suarez-Ruiz In: B.Q. Li and Z.Y. Liu, Editors, Prospects for Coal Science in the 21st Century, Shanxi Science and Technology Press, Shanxi (1999), p. 769.

9. M.J. Iglesias, J.C. del Rio, F. Laggoun-Défarge, A. Jiménez, M.J. Cuesta and I. SuárezRuiz J. Anal. Appl. Pyrol. 62 (2002), p. 1.

10. B. Perrussel, F. Laggoun-Défarge, I. Suarez-Ruiz, A. Jimenez, M.J. Iglesias and J.-N. Rouzaud In: B.Q. Li and Z.Y. Liu, Editors, Prospects for Coal Science in the 21st Century, Shanxi Science and Technology Press, Shanxi (1999), p. 145.

11. M.J. Iglesias, M.J. Cuesta, A. Jiménez, F. Laggoun-Défarge and I. Suárez-Ruiz J. Anal. Appl. Pyrol. 58-59 (2001), p. 841.

12. I. Suarez-Ruiz, L. Martinez, Ph. Bertrand, J.G. Prado and J.R. Disnar Int. J. Coal Geol. 25 (1994), p. 47.

13. P. Landais, R. Michels and B. Poty J. Anal. Appl. Pyrol. 16 (1989), p. 103.

14. F. Laggoun-Défarge, E. Lallier-Vergès, I. Suarez-Ruiz, N. Cohaut, A. Jiménez, P. Landais and J.G. Prado In: P.K. Mukhopadhyay and W.G. Dow, Editors, Vitrinite Reflectance as a Maturity Parameter. Applications and limitations, ACS Symposium Series 570, American Chemical Society, Washington DC (1994), p. 194.

15. F. Laggoun-Défarge, J.-N. Rouzaud, N. Cohaut, P. Landais, E. Lallier-Vergès and I. Suarez-Ruiz, In: J.A. Pajares, J.M.D. Tascon (Eds.), Coal Science, Proc. 8th Int. Conf. Coal Science, Oviedo, September 10-15, 1995, Elsevier, 1995, p. 215.

16. J. Espitalié, G. Deroo and F. Marquis Rev. Inst. Fr. Pétrol. 41/1 784 (1986), p. 73.

17. A. Galvez, N. Herlin-Boime, C. Reynaud, C. Clinard, J.-N. Rouzaud, Carbon (in press).

18. F. Fortin and J.-N. Rouzaud Fuel 72 (1993), p. 245.

19. J.V. Ibarra, E. Munoz and R. Moliner Org. Geochem. 24 (1996), p. 724.

20. M.A. Wilson, R.J. Pugmire, J. Karas, L.B. Alemany, W.R. Woolfenden, D.M. Garnt and P.H. Given Anal. Chem. 56 (1984), p. 933.

21. J.K. Brown, J. Chem. Soc. Lond. (1995) 744.

22. P. Chen, P.W.-J. Yang and P.R. Griffiths Fuel 64 (1985), p. 307.

23. J.-N. Rouzaud, D. Vogt and A. Oberlin Fuel Proc. Technol. 20 (1988), p. 143.

24. A. Jimenez, M.J. Iglesias, F. Laggoun-Défarge and I. Suarez-Ruiz J. Anal. Appl. Pyrol. 50 (1999), p. 117. 